\title{
Computed tomography lymphography by transbronchial injection of iopamidol to identify sentinel nodes in preoperative patients with non-small cell lung cancer: A pilot study
}

\author{
Hiromitsu Takizawa, MD, ${ }^{\mathrm{a}}$ Kazuya Kondo, MD, ${ }^{\mathrm{b}}$ Hiroaki Toba, MD, ${ }^{\mathrm{a}}$ Koichiro Kajiura, MD, \\ Abdellah Hamed Khalil Ali, MD, ${ }^{\mathrm{c}}$ Shoji Sakiyama, MD, ${ }^{\mathrm{a}}$ and Akira Tangoku, MD ${ }^{\mathrm{a}}$
}

\begin{abstract}
Objective: The objective of the present study was to assess the safety and feasibility of computed tomography lymphography by transbronchial injection of a water-soluble extracellular computed tomography contrast agent.

Methods: From April 2010 to May 2011, patients with clinical stage I non-small cell lung cancer who were candidates for lobectomy were enrolled in the present study. An ultrathin bronchoscope was inserted to the target bronchus under the guidance of virtual bronchoscopic navigation images. Computed tomography images of the chest were obtained 0.5 and 5 minutes after 2 or $3 \mathrm{~mL}$ of iopamidol was injected through a microcatheter. Sentinel nodes were identified when the maximum computed tomography attenuation value of the lymph nodes on the postcontrast computed tomography images increased by 30 Hounsfield units or more compared with the precontrast images. Patients underwent lobectomy with standard lymph node dissection.
\end{abstract}

Results: The ultrathin bronchoscope could access the targeted bronchus, and iopamidol was delivered into the peritumoral area in all 13 patients without any complications. Sentinel nodes were identified in $12(92.3 \%)$ of the 13 patients. The average number of sentinel nodes was 1.5 (range, 1-2). Pathologic examination revealed metastatic lymph nodes in 2 patients. Metastatic nodes were included with the sentinel nodes.

Conclusions: Computed tomography lymphography by transbronchial injection of iopamidol was a safe and feasible method to identify the sentinel nodes in patients with clinical stage I non-small cell lung cancer. (J Thorac Cardiovasc Surg 2012;144:94-9)

A sentinel node ( $\mathrm{SN}$ ) is defined as the first node draining a tumor and should be the first site affected by lymphatic dissemination. SN navigation surgery has been developed to reduce the extent of lymphadenectomy, with a consequent reduction in operative mortality and complications, especially in breast cancer and malignant melanoma surgery. ${ }^{1,2}$ However, SN navigation surgery has not been popular for patients with non-small cell lung cancer (NSCLC), because it is not considered necessary. The American College of Surgeons Oncology Group Z0030 study group concluded in their large, prospective, multi-institutional, randomized trial that mediastinal lymph node dissection

From the Department of Thoracic, Endocrine Surgery, and Oncology ${ }^{\mathrm{a}}$ and Oncological Medical Services, ${ }^{\text {b }}$ Institute of Health Bioscience, University of Tokushima Graduate School, Tokushima, Japan; and Department of Respiratory Medicine, ${ }^{\mathrm{c}}$ Sohag University Sohag Faculty of Medicine, Sohag, Egypt.

This work has been supported by the Grant-in-Aid for Young Scientists (B) grant 22791312 of the Ministry of Education, Culture, Sports, Science, and Technology (MEXT) from 2010 to 2011.

Disclosures: Authors have nothing to disclose with regard to commercial support.

Received for publication Oct 22, 2011; revisions received Feb 14, 2012; accepted for publication March 16, 2012; available ahead of print April 16, 2012.

Address for reprints: Hiromitsu Takizawa, MD, Department of Thoracic, Endocrine Surgery, and Oncology, Institute of Health Bioscience, University of Tokushima Graduate School, 3-18-15, Kuramotocho, Tokushima 770-8503, Japan (E-mail: htakizawa@clin.med.tokushima-u.ac.jp)

0022-5223/\$36.00

Copyright $($ C 2012 by The American Association for Thoracic Surgery doi:10.1016/j.jtcvs.2012.03.040 did not increase operative mortality or the number or type of complications compared with lymph node sampling in patients with early-stage NSCLC. ${ }^{3}$

However, the background of patients with NSCLC has been changing. Recently, with the increased incidence of small-size NSCLC, segmentectomy is again under evaluation for clinical stage T1aNO NSCLC. ${ }^{4}$ Several reports have demonstrated that survival and local recurrence were similar between patients treated with segmentectomy and those treated with lobectomy. ${ }^{5-8}$ The most important issue regarding this comparison is whether postoperative local recurrence is increased by segmentectomy. In the ongoing trial and previous reports regarding segmentectomy, the eligibility criteria for segmentectomy included a prerequisite of no lymph node metastasis by intraoperative findings because node-positive cases have a chance to be locoregionally controlled and to be correctly staged by converting to lobectomy. ${ }^{4-8}$ Patients with clinical stage IA NSCLC had an incidence of pathologic stage N1 and $\mathrm{N} 2$ of $4.8 \%$ to $7.6 \%$ and $9.5 \%$ to $13.3 \%$, respectively. ${ }^{9,10}$ Also, skip metastasis to the mediastinal lymph nodes has been reported in $18 \%$ to $30 \%$ of patients with NSCLC. ${ }^{11-13}$ Therefore, intraoperative sampling and frozen section analysis of the true $\mathrm{SNs}$ is important in ensuring the radicality of segmentectomy.

We have developed a novel method of computed tomography lymphography (CTLG) with transbronchial injection 


\section{Abbreviations and Acronyms}

CTLG = computed tomography lymphography

MDCT $=$ multidetector computed tomography

NSCLC $=$ non-small cell lung cancer

$\mathrm{SN}=$ sentinel node

of a water-soluble extracellular CT contrast agent of iopamidol. This method aims to identify the SNs in patients with preoperative NSCLC. The present report shows a new technique of CTLG by transbronchial injection of iopamidol, and the purpose of the present study was to evaluate the safety and feasibility of this method.

\section{METHODS \\ Eligibility}

From April 2010 to May 2011, patients with clinical stage I NSCLC, who were candidates for lobectomy with standard hilar and mediastinal lymph node dissection, were enrolled in the present study. Patients were excluded if they had an allergy to iodinated contrast medium or a history of asthma. The ethics committee of Tokushima University Hospital approved the study protocol for CTLG with transbronchial injection of iopamidol in March 2010. All patients provided informed consent.

\section{Objective}

The objective of the study was to assess the safety and feasibility of newly developed CTLG with transbronchial injection of iopamidol.

\section{CTLG Technique With Transbronchial Injection of Iopamidol}

Virtual bronchoscopic navigation images were rendered using Bf-NAVI (Olympus, Tokyo, Japan) using 1-mm-thickness multidetector CT (MDCT) scan data before CTLG. Before lymphography, CT was performed using a MDCT scanner (Somatom Sensation 16; Siemens, Erlangen, Germany) with the following parameters: $120 \mathrm{kV}, 0.75 \mathrm{~mm}$ collimation, 16 detectors, pitch 0.95 , and rotation time 0.5 second. All lung fields were scanned during single breath-hold inhalations. Patients received mild sedation with 1 to $2 \mathrm{mg}$ of midazolam. Local anesthesia of the upper respiratory tract was induced with $4 \%$ lidocaine. After a brief observation of the tracheobronchial lumen using a conventional bronchoscope (BF type 260; Olympus; external diameter, $4.9 \mathrm{~mm}$ ), an ultrathin bronchoscope (BF type XP260F; Olympus: external diameter, $2.8 \mathrm{~mm}$ ) was advanced as far as possible to the target bronchus by comparing the direct vision and navigation images. A microcatheter (FasTracker-325, Boston Scientific, Tokyo, Japan) was inserted through a channel in the ultrathin bronchoscope, and the tip of the catheter was adjusted using C-arm fluoroscopy guidance. After the ultrathin bronchoscope was detached from the light source and video processor while the tip of the catheter and bronchoscope remained inserted in the target bronchus, the patient table was slid into the CT scanner. A 5-mL syringe was attached to the microcatheter and 2 or $3 \mathrm{~mL}$ of iopamidol (Iopamiron-300; Bayer HealthCare, Osaka, Japan) was injected transbronchially into the peritumoral area. Iopamiron-300 has a molecular weight of 777.09 Daltons, the solute has an iodine concentration of $300 \mathrm{mg} / \mathrm{mL}$, the viscosity is $4.4 \mathrm{mPa} / \mathrm{s}$, and the osmolarity is less than 3 times the osmolarity of physiologic saline. After the microcatheter and ultrathin bronchoscope were removed from the patient, MDCT images (1-mm thickness) of the chest were obtained 0.5 and 5 minutes after injection, according to our preliminary data comparing 3 cases (data not shown).

\section{SN Identification}

Respective CTLG and contrast-enhanced CT images were checked simultaneously on a workstation (Aquarius Net Station, version 4; Tera Recon, San Mateo, Calif). The maximum CT attenuation value of all lymph nodes, including the pulmonary, hilar, and mediastinal lymph nodes, was measured by circling the lymph nodes in the region of interest. A lymph node was defined as the SN when the maximum CT value of the lymph node on the postcontrast CT images ( 0.5 minutes after injection) increased by 30 Hounsfield units (HU) or more compared with that on the precontrast images. The maximum CT values are presented as the mean \pm standard deviation. Nodal classification was determined according to the Unio Internationalis Contra Cancrum staging system, version $7 .{ }^{14} \mathrm{~A} 3$-dimensional CT image was reconstructed on the same workstation using 1-mm-thickness MDCT images.

\section{Surgery and Pathologic Examination}

Patients underwent video-assisted thoracic surgery lobectomy with standard hilar and mediastinal lymph node dissection ( 2 or 3 ports and 4-8-cm access incision without rib spreading devices). SNs were harvested according to the CTLG findings, including the 2- and 3-dimensional images. The SNs in the intrapulmonary stations were harvested on the back table, and the SNs in the hilar and mediastinal stations were harvested before lobectomy. All lymph nodes, including the SNs, were histopathologically examined using standard hematoxylin and eosin staining. The TNM classification was determined according to the Unio Internationalis Contra Cancrum staging system, version 7.

\section{RESULTS}

Fourteen patients with clinical stage I NSCLC (or suspected of having NSCLC) were enrolled in the present study. One patient was excluded because the intraoperative frozen section analysis revealed that the lesion had inflammatory changes. The 13 patients included 4 men and 9 women, with a mean age of 65.7 years (range, $47-76$ years). The mean tumor size was $2.1 \mathrm{~mm}$ (range, $1.4-3.4 \mathrm{~mm}$ ). The histologic type was adenocarcinoma in 11 patients and squamous cell carcinoma in 2. The tumor location was the right upper lobe in 7 , right lower lobe in 2 , left upper lobe in 3 , and left lower lobe in 1 . The pathologic TNM stage was T1aN0M0 in 5, T1bN0M0 in 2, T2aNOM0 in 4, T1bN1M0 in 1, and T1aN2M0 in 1 (Table 1). The tumor locations and target bronchi are listed in Table 2. The virtual bronchoscopic images displayed the routes to a median of the fifth bronchus (third to sixth).

CTLG was usually performed after CT-guided transbronchial tumor biopsy (10/13) or a CT-guided metallic coil marking (1/13) and was accomplished within 10 minutes. The ultrathin bronchoscope accessed the targeted bronchus, and iopamidol was delivered into the peritumoral area in all patients without any complications (Figure 1). In several cases, oval-shaped lymph nodes were clearly enhanced on the postlymphography CT images (Figure 2, C). Three-dimensional $\mathrm{CT}$ images rendered by $1-\mathrm{mm}$ thickness MDCT images 0.5 minute after CT lymphography clarified the position of a SN and the structure of the hilum (Figure 2,D). Lymphatic vessels were visualized as stream lines in 2 patients (Figure 3 ).

SNs were identified in $12(92.3 \%)$ of the 13 patients, and the average number of SNs was 1.5 (range, 1-2). SNs were 
TABLE 1. Patient characteristics

\begin{tabular}{lc}
\hline \multicolumn{1}{c}{ Characteristic } & Value \\
\hline Age (y) & $65.7 \pm 7.6$ \\
Gender & \\
Male & 4 \\
Female & 9 \\
Tumor size (cm) & $2.1 \pm 0.6$ \\
Tumor location & \\
RUL & 7 \\
RLL & 2 \\
LUL & 3 \\
LLL & 1 \\
Histologic type & \\
Adenocarcinoma & 11 \\
Squamous cell carcinoma & 2 \\
Pathologic TNM stage & \\
T1aN0M0 & 5 \\
T1bN0M0 & 2 \\
T2aN0M0 & 4 \\
T1bN1M0 & 1 \\
T1aN2M0 & 1 \\
\hline
\end{tabular}

Data presented as mean \pm standard deviation or numbers. $R U L$, Right upper lobe; $R L L$, right lower lobe; $L U L$, left upper lobe; $L L L$, left lower lobe.

identified at the pulmonary or hilar station in all patients and the mediastinal station in 4 patients. The maximum CT value of the SNs on the precontrast and postcontrast images 0.5 and 5 minutes after injection was $111 \pm 32 \mathrm{HU}, 269 \pm$ $243 \mathrm{HU}$, and $204 \pm 184 \mathrm{HU}$, respectively. Of the 12 patients in whom SNs were detected, 10 had no metastasis in the SNs and no metastasis in the other lymph nodes. In patient 4, CTLG identified SNs in stations 5 and 13, and pathologic examination revealed a solo skip metastasis to the mediastinum in station 5. In patient 11, CTLG identified SNs in stations 2 and 10, and a pathologic examination revealed metastatic lymph nodes in stations 10 and 11.

\section{DISCUSSION}

Limited numbers of studies have reported SN identification for patients with NSCLC. SN biopsy using isosulfan blue dye showed an unsatisfactorily low detection rate caused by anthracotic black lymph nodes. ${ }^{15}$ The Cancer and Leukemia Group B 140203 trial failed to show a satisfactory SN identification rate using a radiolabeled tracer because of the aerosolization of radioactivity and shinethrough effect, making it difficult to evaluate the pulmonary and hilar lymph nodes. ${ }^{16}$ In contrast, Nomori and colleagues ${ }^{17}$ reported a SN identification rate of $83 \%$ in the SN navigation segmentectomy trial adopting the ex vivo SN identification method. However, their method requires surgeons to perform segmentectomy before SN identification and when intraoperative frozen section analysis of the SNs showed metastasis, conversion to lobectomy must be done. The radiolabeled tracer method has the disadvantage of exposing both patients and surgeons to radiation. Yamashita and colleagues ${ }^{18}$ reported an $\mathrm{SN}$ identification rate of $80.7 \%$ using a video-assisted thoracoscopic indocyanine green fluorescence imaging system. Because infrared light cannot reach lymph nodes located deeply in the lung parenchyma or mediastinal fat tissue, ex vivo SN identification is needed to achieve as accurate an evaluation as that produced using the radiolabeled tracer method. In 2004, Suga and colleagues ${ }^{19}$ reported a method of $\mathrm{SN}$ identification using a CT-guided percutaneous injection of iopamidol into peritumoral lung tissue. They successfully identified SNs in all 9 patients with preoperative NSCLC without any complications. However, in 2006, the same group reported that cerebral air embolisms occurred using this method. ${ }^{20}$ Air embolism is a rare, but potentially lethal, complication encountered during percutaneous transthoracic needle biopsy or marking. ${ }^{21,22}$ The percutaneous transthoracic approach also has other potential risks, including

TABLE 2. Tumor location and sentinel lymph node station

\begin{tabular}{|c|c|c|c|c|c|c|c|c|c|c|c|c|}
\hline Pt. no. & $\begin{array}{l}\text { Age } \\
(y)\end{array}$ & Gender & $\begin{array}{c}\text { Tumor } \\
\text { size }(\mathrm{cm})\end{array}$ & $\begin{array}{c}\text { Histologic } \\
\text { type }\end{array}$ & $\begin{array}{c}\text { Tumor } \\
\text { location }\end{array}$ & $\begin{array}{l}\text { Targeted } \\
\text { bronchus }\end{array}$ & $\begin{array}{c}\text { Iopamidol } \\
\text { volume }(\mathrm{mL})\end{array}$ & $\begin{array}{c}\text { SN } \\
\text { station }\end{array}$ & $\begin{array}{l}\text { SNs } \\
\text { (n) }\end{array}$ & $\begin{array}{l}\text { Metastatic } \\
\text { station }\end{array}$ & $\begin{array}{c}\text { Resected } \\
\text { LN (n) }\end{array}$ & $\begin{array}{c}\text { Pathologic } \\
\text { stage }\end{array}$ \\
\hline 1 & 64 & $\mathrm{~F}$ & 2.3 & ACA & Right S3 & Right B3ai $\alpha \mathrm{x}$ & 2 & $4 \mathrm{R}, 12$ & 2 & - & 22 & IA \\
\hline 2 & 64 & $\mathrm{~F}$ & 1.6 & ACA & Right S3b & Right B3bii $\alpha \mathrm{x}$ & 2 & 11 & 1 & - & 18 & IA \\
\hline 3 & 70 & $\mathrm{~F}$ & 2.2 & ACA & Right S3 & Right B3ai & 2 & 11 & 1 & 一 & 16 & IA \\
\hline 4 & 61 & M & 1.5 & ACA & Left $\mathrm{S} 1+2$ & Left B1+2aii $\beta y$ & 2 & 5,13 & 2 & 5 & 13 & IIIA \\
\hline 5 & 76 & $\mathrm{~F}$ & 3.2 & ACA & Left S9 & Left B9bii $\beta$ x & 2 & 7,12 & 2 & - & 23 & IB \\
\hline 6 & 47 & $\mathrm{~F}$ & 2.0 & ACA & Right S9 & Right B9bii $\beta y$ & 2 & 13 & 1 & - & 7 & IA \\
\hline 7 & 65 & $\mathrm{~F}$ & 1.6 & ACA & Right S9a & Right B9ai & 2 & 11 & 1 & - & 13 & IA \\
\hline 8 & 68 & $\mathrm{~F}$ & 1.4 & ACA & Right S2b & Right B2bi $\alpha$ & 3 & 12 & 2 & - & 10 & IB \\
\hline 9 & 66 & M & 2.2 & SCC & Right S2 & Right B2aii $\alpha$ & 3 & 11,12 & 2 & - & 27 & IB \\
\hline 10 & 59 & M & 1.8 & ACA & Left $\mathrm{S} 1+2 \mathrm{a}$ & Left B1+2ai & 3 & 13 & 1 & - & 10 & IA \\
\hline 11 & 76 & $\mathrm{~F}$ & 2.4 & ACA & Right S1 & Right B1b & 3 & $2 \mathrm{R}, 10$ & 2 & 10,11 & 12 & IIA \\
\hline 12 & 67 & $\mathrm{~F}$ & 2.0 & ACA & Right S2 & Right B2bii $\alpha$ & 3 & - & - & - & 6 & IA \\
\hline 13 & 71 & M & 3.4 & SCC & Left B4 & Left B4bii & 3 & 10,13 & 2 & - & 25 & IB \\
\hline
\end{tabular}

The branch of the bronchus, which extends to superior, dorsal, or lateral side, was defined as i, $\alpha$, or $\mathrm{x}$; the branch of the bronchus, which extends to inferior ventral or medial side, was defined as ii, $\beta$, or y. Pt. no., Patient number; $S N$, sentinel lymph node; $L N$, lymph node; $F$, female; $A C A$, adenocarcinoma; $S$, segment of lung; $M$, male; $S C C$, squamous cell carcinoma. 


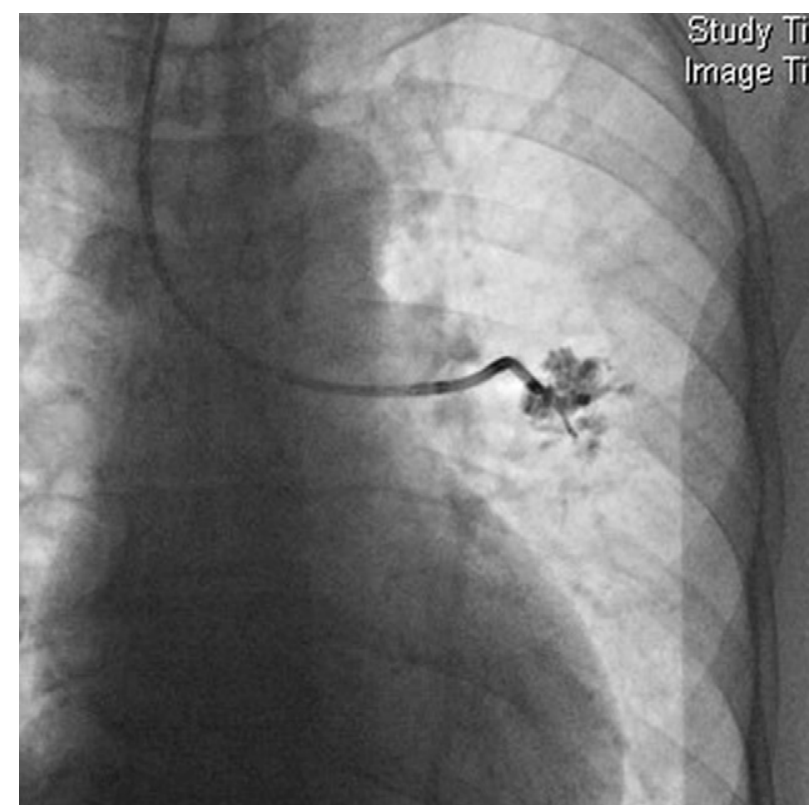

FIGURE 1. Fluoroscopy finding during lymphography showing iopamidol injected into the peripheral bronchioalveolar area near the tumor through the ultrathin bronchoscope.

pneumothorax, bleeding, and pleural tumor seeding. Highrisk examinations are not acceptable for patients with earlystage NSCLC.
Theoretically, our method has the following advantages compared with previous methods. First, the transbronchial approach is free of the risk of pneumothorax, bleeding, and pleural tumor seeding compared with the percutaneous transthoracic approach. Second, CTLG does not expose surgeons to radiation. Third, CTLG can detect lymph nodes located deeply in the lung parenchyma or mediastinal fat tissue. Also, the surgeons can understand the location of the identified SNs preoperatively by interpreting the postCTLG images, which demonstrate the position of the SNs and the structure of the hilum or mediastinum. Finally, because it is not necessary to dissect all lymph nodes to identify SNs, surgeons only have to sample the SNs identified preoperatively using CTLG and submit them for intraoperative pathologic diagnosis. However, if the SNs show metastasis, the segmentectomy should be converted to lobectomy.

CTLG by transbronchial injection of iopamidol was safely performed in 14 patients with preoperative NSCLC without any complications. Virtual bronchoscopic images displayed routes to a median of the fifth bronchus (third to sixth), the ultrathin bronchoscope could access the targeted bronchus, and iopamidol was delivered into the peritumoral area in all 13 patients. The method was usually combined with CT-guided transbronchial lung biopsy or metallic coil marking, and it took about 10 minutes to

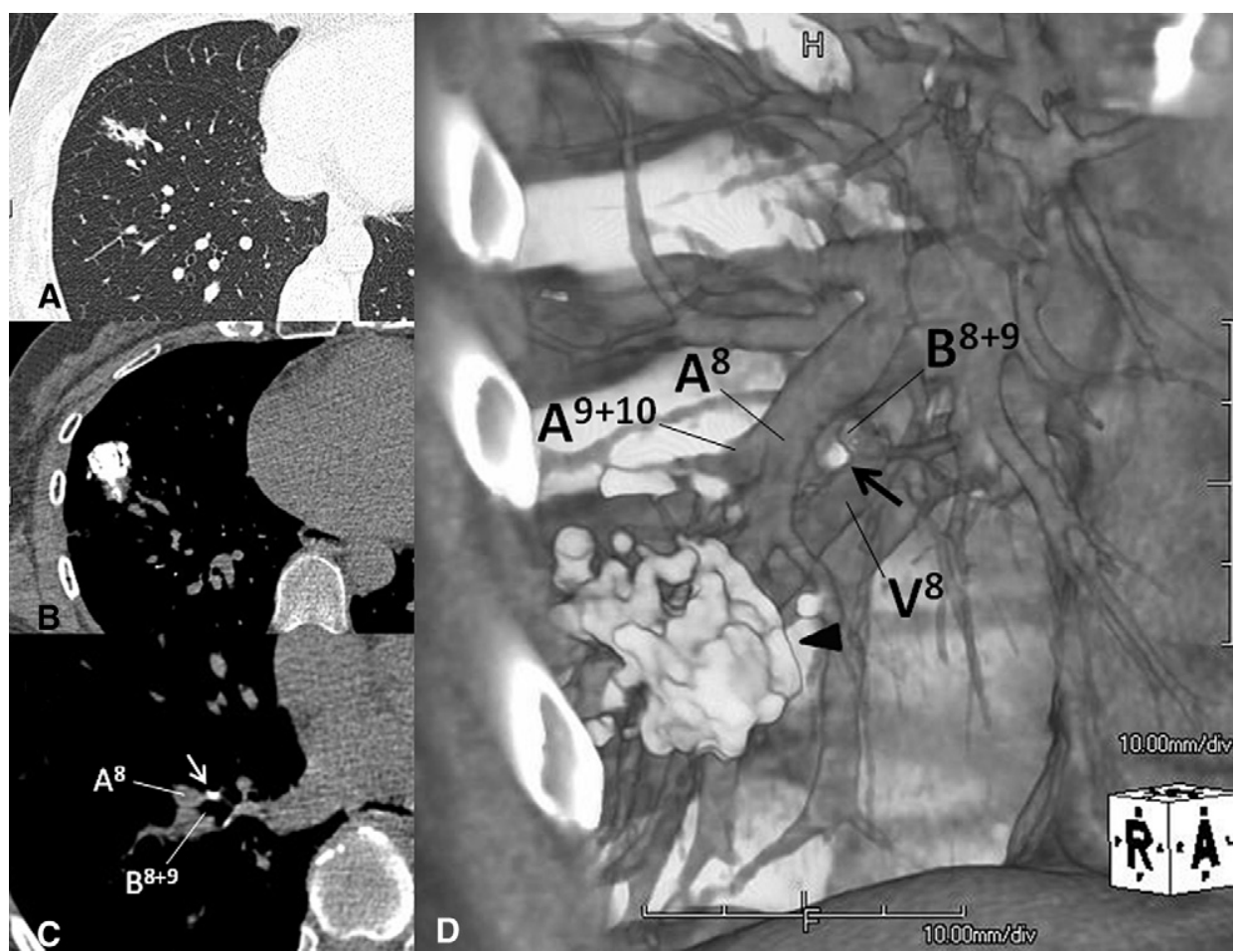

FIGURE 2. Computed tomography (CT) lymphography in patient 7 in Table 2 . A, A tumor diameter of $1.6 \mathrm{~cm}$ is seen in right station 9 a on a prelymphography CT (CTLG) image. B, Iopamidol is delivered into the peritumoral lung tissue of right station 9. C, An oval-shaped lymph node is clearly enhanced on a postCTLG image (arrow). D, Three-dimensional CT image rendered by 1-mm-thickness multidetector CT images 0.5 minute after CTLG clarifies the position of a sentinel lymph node and the structure of the hilum. Arrows, a sentinel node; arrowhead, iopamidol injected into the peritumoral lung tissue. 


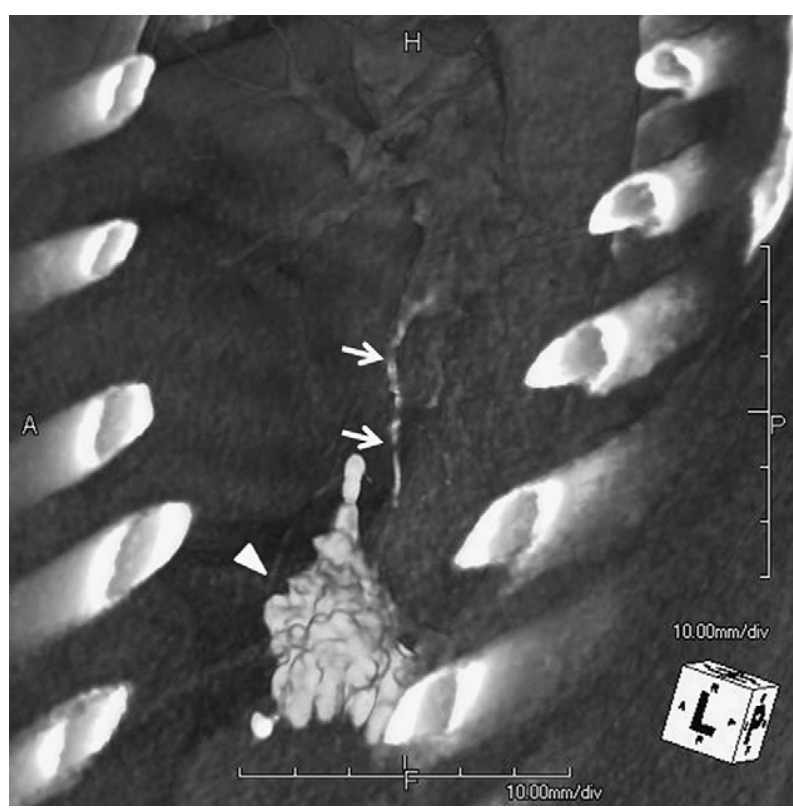

FIGURE 3. Three-dimensional computed tomography (CT) image rendered by $1-\mathrm{mm}$-thickness multidetector CT images 0.5 minute after CT lymphography showing a lymphatic vessel (patient 5 in Table 2). Arrows, A lymphatic vessel; arrowheads, iopamidol injected into peritumoral lung tissue.

complete the CTLG method itself. The SN identification rate of our CTLG method was $92.3 \%$, which was better than that using previous methods. ${ }^{15-19}$ Pathologic examination revealed metastatic lymph nodes in 2 patients. The metastatic nodes were included in the SNs. We could not identify any SNs in 1 patient (patient 12), in whom several mediastinal lymph nodes had small calcifications. Although the reason no lymph nodes were enhanced in this case is unclear, there might be difficulty in identifying SNs in patients with a history of tuberculosis.

The present study had some limitations and issues when CTLG is adopted for SN navigation segmentectomy. First, 2 patients with pathologically confirmed metastases to the lymph nodes were insufficient to assess the accuracy of CTLG. Second, the potential of CTLG in identifying intrapulmonary SNs before segmentectomy needs to be evaluated in another study, because SNs in stations 12 and 13 were harvested on the back table in the present study and SNs in the hilar and mediastinal stations were harvested before lobectomy. Finally, the development of high-accuracy intraoperative pathologic or genetic evaluations combined with CTLG for SN identification is required in future studies.

Previous reports regarding CTLG for patients with breast cancer showed that lymphatic vessels could be visualized clearly as stream lines from the injection site to the axillary SNs. ${ }^{23}$ In the present study, lymphatic vessels were visualized as stream lines in only 2 patients. In most cases, bronchi that reached a segment including tumor were diffusely enhanced on the post-CTLG images. These findings indicate that the lymphatic networks of the lung densely surround the bronchi and that these networks are responsible for the diversity of lymphatic spread in patients with NSCLC. Suga and colleagues ${ }^{19}$ also reported that bronchi were diffusely enhanced on their CTLG images using the percutaneous transthoracic injection of iopamidol.

In the present study, the maximum CT value of the SNs at 0.5 minute was greater than at 5 minutes after injection of the contrast agent. We set the timing of the CT scan according to our preliminary data comparing 3 cases: 0.5 versus 5, 1 versus 10, and 2 versus 15 minutes after injection (data not shown). The former times showed better visualization of the enhanced SNs than the latter times in each comparison, and the pairing of 0.5 and 5 minutes showed the best visualization. Suga and colleagues ${ }^{19}$ performed CT scans every minute for 5 minutes after percutaneous transthoracic injection of iopamidol. They showed that the maximum CT value of the SN had reached its peak at 1 minute and then tapered, indicating that increased interstitial pressure when a contrast agent is injected is one of the most important factors influencing the volume of contrast agent that penetrates into the lymphatic systems during CTLG.

\section{CONCLUSIONS}

CTLG by transbronchial injection of iopamidol was a safe and useful method to identify SNs in preoperative patients with NSCLC. The post-CTLG images clarified the position of the SNs and the structure of the hilum, which could help surgeons to acquire an intuitive image during $\mathrm{SN}$ navigation segmentectomy. Although these results are preliminary, this method has the potential to improve the accuracy of SN biopsy during segmentectomy in patients with NSCLC.

\section{References}

1. Krag DN, Weaver DL, Alex JC, Fairbank JT. Surgical resection and radiolocalization of the sentinel lymph node in breast cancer using a gamma probe. Surg Oncol. 1993;2:335-9.

2. Morton DL, Wen DR, Wong JH, Economou JS, Cagle LA, Storm FK, et al. Technical details of intraoperative lymphatic mapping for early stage melanoma. Arch Surg. 1992;127:392-9.

3. Allen MS, Darling GE, Pechet TT, Mitchell JD, Herndon JE II, Landreneau RJ, et al., ACOSOG Z0030 Study Group. Morbidity and mortality of major pulmonary resections in patients with early-stage lung cancer: initial results of the randomized, prospective ACOSOG Z0030 trial. Ann Thorac Surg. 2006;81:1013-9.

4. Nakamura K, Saji H, Nakajima R, Okada M, Asamura H, Shibata T, et al. A phase III randomized trial of lobectomy versus limited resection for smallsized peripheral non-small cell lung cancer (JCOG0802/WJOG4607L). Jpn J Clin Oncol. 2010;40:271-4.

5. Okada M, Nishio W, Sakamoto T, Uchino K, Yuki T, Nakagawa A, et al. Effect of tumor size on prognosis in patients with non-small cell lung cancer: the role of segmentectomy as a type of lesser resection. J Thorac Cardiovasc Surg. 2005; 129:87-93.

6. Koike T, Yamato Y, Yoshiya K, Shimoyama T, Suzuki R. Intentional limited pulmonary resection for peripheral T1 N0 M0 small-sized lung cancer. J Thorac Cardiovasc Surg. 2003;125:924-8. 
7. Kodama K, Doi O, Higashiyama M, Yokouchi H. Intentional limited resection for selected patients with T1 N0 M0 non-small-cell lung cancer: a singleinstitution study. J Thorac Cardiovasc Surg. 1997;114:347-53.

8. Yoshikawa K, Tsubota N, Kodama K, Ayabe H, Taki T, Mori T. Prospective study of extended segmentectomy for small lung tumors: the final report. Ann Thorac Surg. 2002;73:1055-8.

9. Park HK, Jeon K, Koh WJ, Suh GY, Kim H, Kwon OJ, et al. Occult nodal metastasis in patients with non-small cell lung cancer at clinical stage IA by PET/ CT. Respirology. 2010;15:1179-84.

10. Watanabe S, Oda M, Go T, Tsunezuka Y, Ohta Y, Watanabe Y, et al. Should mediastinal nodal dissection be routinely undertaken in patients with peripheral small-sized ( $2 \mathrm{~cm}$ or less) lung cancer? Retrospective analysis of 225 patients. Eur J Cardiothorac Surg. 2001;20:1007-11.

11. Lic N, Petricevic A, Arar D, Kotarac S, Banovic J, Ilic NF, et al. Skip mediastinal nodal metastases in the IIIa/N2 non-small cell lung cancer. J Thorac Oncol. 2007; 2:1018-21.

12. Benoit L, Anusca A, Ortega-Deballon P, Cheynel N, Bernard A, Favre JP. Analysis of risk factors for skip lymphatic metastasis and their prognostic value in operated N2 non-small-cell lung carcinoma. Eur J Surg Oncol. 2006;32: 583-7.

13. Gómez-Caro A, Garcia S, Reguart N, Arguis P, Sanchez M, Gimferrer JM, et al. Incidence of occult mediastinal node involvement in cN0 non-smallcell lung cancer patients after negative uptake of positron emission tomography/computer tomography scan. Eur J Cardiothorac Surg. 2010;37: 1168-74.

14. Goldstraw P, Crowley J, Chansky K, Giroux DJ, Groome PA, Rami-Porta R, et al. The IASLC Lung Cancer Staging Project: proposals for the revision of the TNM stage groupings in the forthcoming (seventh) edition of the TNM classification of malignant tumours. J Thorac Oncol. 2007;2:706-14.
15. Little AG, DeHoyos A, Kirgan DM, Arcomano TR, Murray KD. Intraoperative lymphatic mapping for non-small cell lung cancer: the sentinel node technique. J Thorac Cardiovasc Surg. 1999;117:220-4.

16. Liptay MJ, D'Amico TA, Nwogu C, Demmy TL, Wang XF, Gu L, et al., Thoracic Surgery Subcommittee of the Cancer and Leukemia Group B. Intraoperative sentinel node mapping with technitium-99 in lung cancer: results of CALGB 140203 multicenter phase II trial. J Thorac Oncol. 2009;4:198-202.

17. Nomori H, Ikeda K, Mori T, Kobayashi H, Iwatani K, Kawanaka K, et al. Sentine node navigation segmentectomy for clinical stage IA non-small cell lung cancer. J Thorac Cardiovasc Surg. 2007;133:780-5.

18. Yamashita S, Tokuishi K, Anami K, Miyawaki M, Moroga T, Kamei M, et al Video-assisted thoracoscopic indocyanine green fluorescence imaging system shows sentinel lymph nodes in non-small-cell lung cancer. J Thorac Cardiovasc Surg. 2011;141:141-4.

19. Suga K, Yuan Y, Ueda K, Kaneda Y, Kawakami Y, Zaki M, et al. Computed tomography lymphography with intrapulmonary injection of iopamidol for sentinel lymph node localization. Invest Radiol. 2004;39:313-24.

20. Ueda K, Kaneda Y, Sudo M, Jinbo M, Suga K, Hamono K. Cerebral air embolism during imaging of a sentinel lymphatic drainage in the respiratory tract. Ann Thorac Surg. 2006;81:721-3.

21. Sakiyama S, Kondo K, Matsuoka H, Yoshida M, Miyoshi T, Yoshida S, et al. Fatal air embolism during computed tomography-guided pulmonary marking with a hook-type marker. J Thorac Cardiovasc Surg. 2003;126:1207-9.

22. Kodama F, Ogawa T, Hashimoto M, Tanabe Y, Suto Y, Kato T. Fatal air embolism as a complication of CT-guided needle biopsy of the lung. J Comput Assist Tomogr. 1999;23:949-51.

23. Tangoku A, Yamamoto S, Suga K, Ueda K, Nagashima Y, Hida M, et al. Sentine lymph node biopsy using computed tomography-lymphography in patients with breast cancer. Surgery. 2004;135:258-65. 